\title{
Design and Synthesis of Asymmetric Acyclic Phospholipid Bolaamphiphiles
}

\author{
Toshitsugu Kai ${ }^{1}$, Xue-Long Sun ${ }^{1, \dagger}$, Keith M. Faucher ${ }^{1}$, Robert P. Apkarian ${ }^{2}$, \\ and Elliot L. Chaikof ${ }^{1,3, \dagger}$ \\ ${ }^{1}$ Departments of Surgery and Biomedical Engineering, Emory University School of \\ Medicine, ${ }^{2}$ Integrated Microscopy \& Microanalytical Facility, Emory University, \\ Atlanta, GA 30322, and ${ }^{3}$ School of Chemical and Biomolecular Engineering, Georgia \\ Institute of Technology, Atlanta, GA 30332
}

Submitted as Supporting Information for an Article to Journal of Organic Chemistry

$\dagger$ Address correspondence to:

Xue-Long Sun Ph.D. or Elliot L. Chaikof, M.D., Ph.D. Emory University

1639 Pierce Drive, Rm 5105

Atlanta, GA 30322

Tel: (404) 727-8413; (404) 727-8027

Fax: (404)-727-3660

E-mail: xsun@emory.edu or echaiko@emory.edu 


\section{Table of Contents}

$\begin{array}{ll}\text { General Methods } & \text { S3 }\end{array}$

Supplementary Fig. $1 .{ }^{1} \mathrm{H}$ and ${ }^{13} \mathrm{C}$ NMR spectra of compound 8a $\quad$ S4

Supplementary Fig. 2. ${ }^{1} \mathrm{H}$ and ${ }^{13} \mathrm{C}$ NMR spectra of compound 9a S5

Supplementary Fig. 3. ${ }^{1} \mathrm{H}$ and ${ }^{13} \mathrm{C}$ NMR spectra of compound 10a $\quad$ S6

Supplementary Fig. 4. ${ }^{1} \mathrm{H}$ and ${ }^{13} \mathrm{C}$ NMR spectra of compound 18a $\quad$ S7

Supplementary Fig. 5. ${ }^{1} \mathrm{H}$ and ${ }^{13} \mathrm{C}$ NMR spectra of compound 19a $\quad$ S8

Supplementary Fig. 6. ${ }^{1} \mathrm{H}$ and ${ }^{13} \mathrm{C}$ NMR spectra of compound 20a $\quad$ S9

Supplementary Fig. 7. ${ }^{1} \mathrm{H}$ and ${ }^{13} \mathrm{C}$ NMR spectra of compound 21a $\quad$ S10 
General Methods. TLC was performed on silica gel aluminum-backed plates $\left(\mathrm{F}_{254}, 250\right.$ $\mathrm{mm}$ thickness) and detected by fluorescence quenching or phosphomolybdic acid (20 wt $\%$ in ethanol) with $\mathrm{R}_{\mathrm{f}}$ value around 0.2 to 0.4 for all intermediates and final compounds at the column chromatography elution conditions. Column chromatography was performed using silica gel (230-400 mesh). ${ }^{1} \mathrm{H}$ NMR spectra were recorded at $300 \mathrm{MHz}$ in $\mathrm{CDCl}_{3}$, $\mathrm{CD}_{3} \mathrm{OD}$ (internal $\mathrm{Me}_{4} \mathrm{Si}, \mathrm{d}=0$ ) at the sample concentration of $5 \mathrm{mg} / 0.6 \mathrm{~mL}$. Infrared spectra of test samples in powder and water-casted solution form were acquired using a Fourier Transform Infrared (FT-IR) spectrometer equipped with a wide band MCT detector. Dipalmitolyphosphatidylcholine (DPPC) was purchased from Avanti Polar Lipids (Alabaster, AL). 

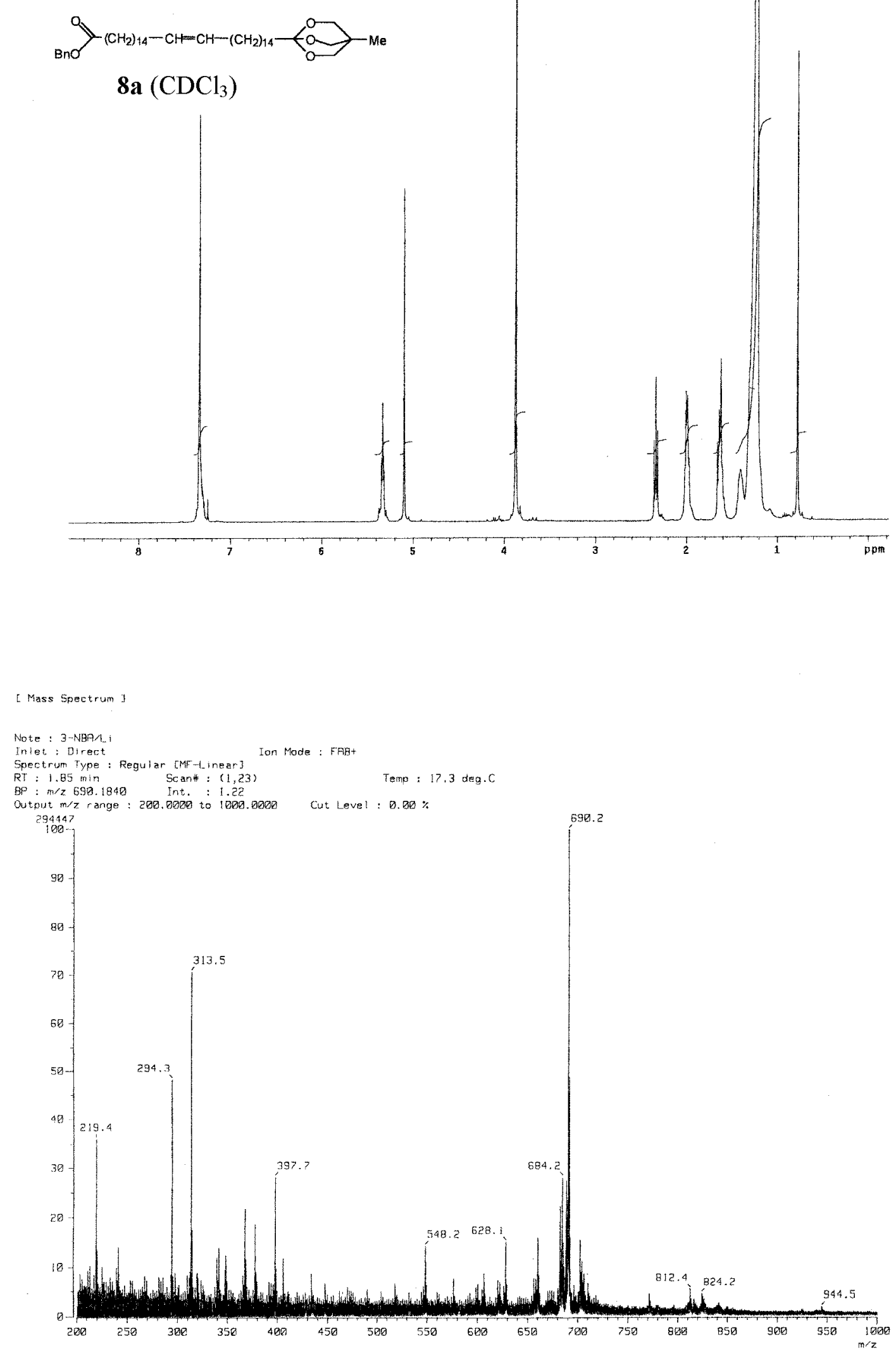

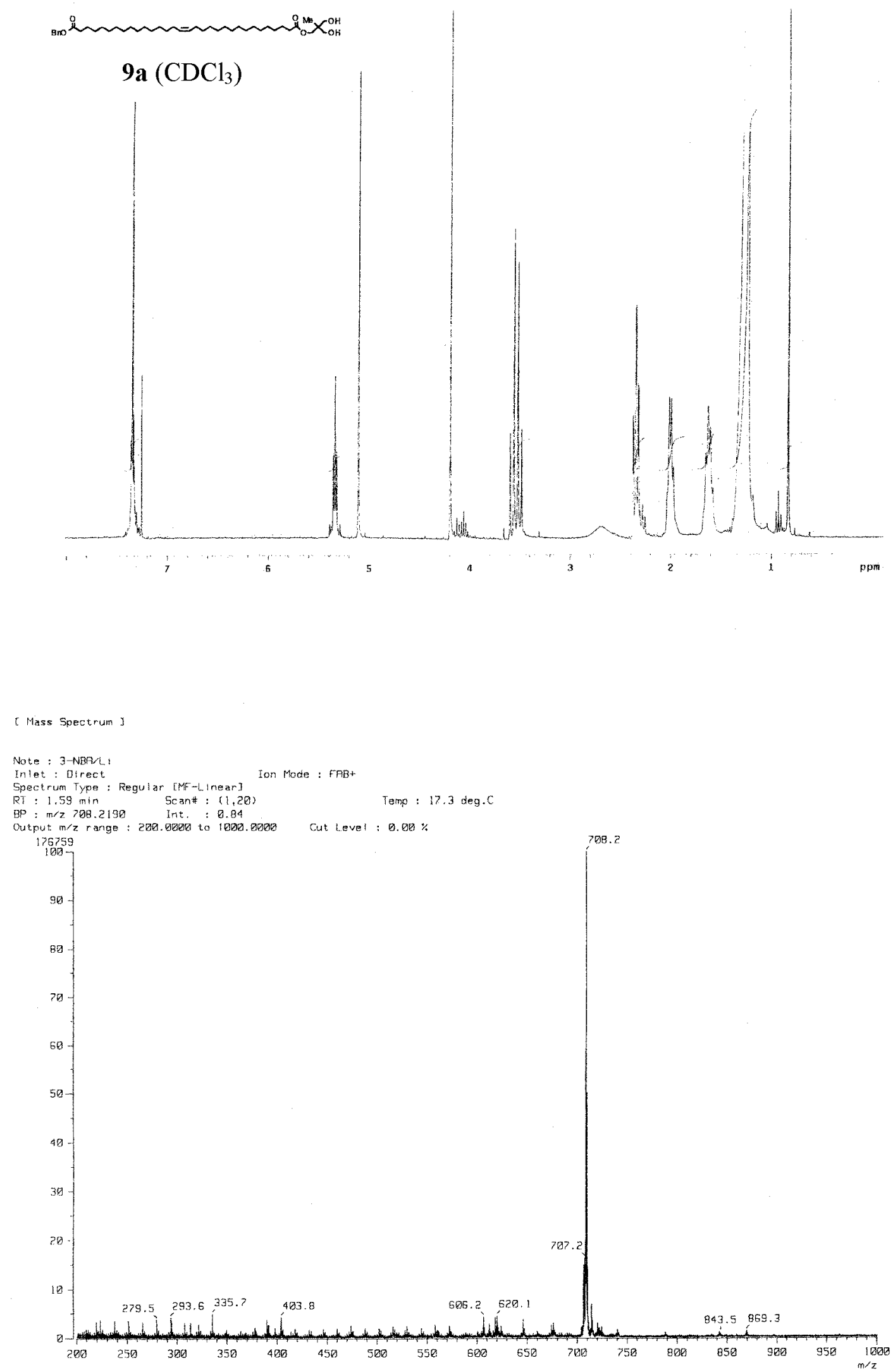

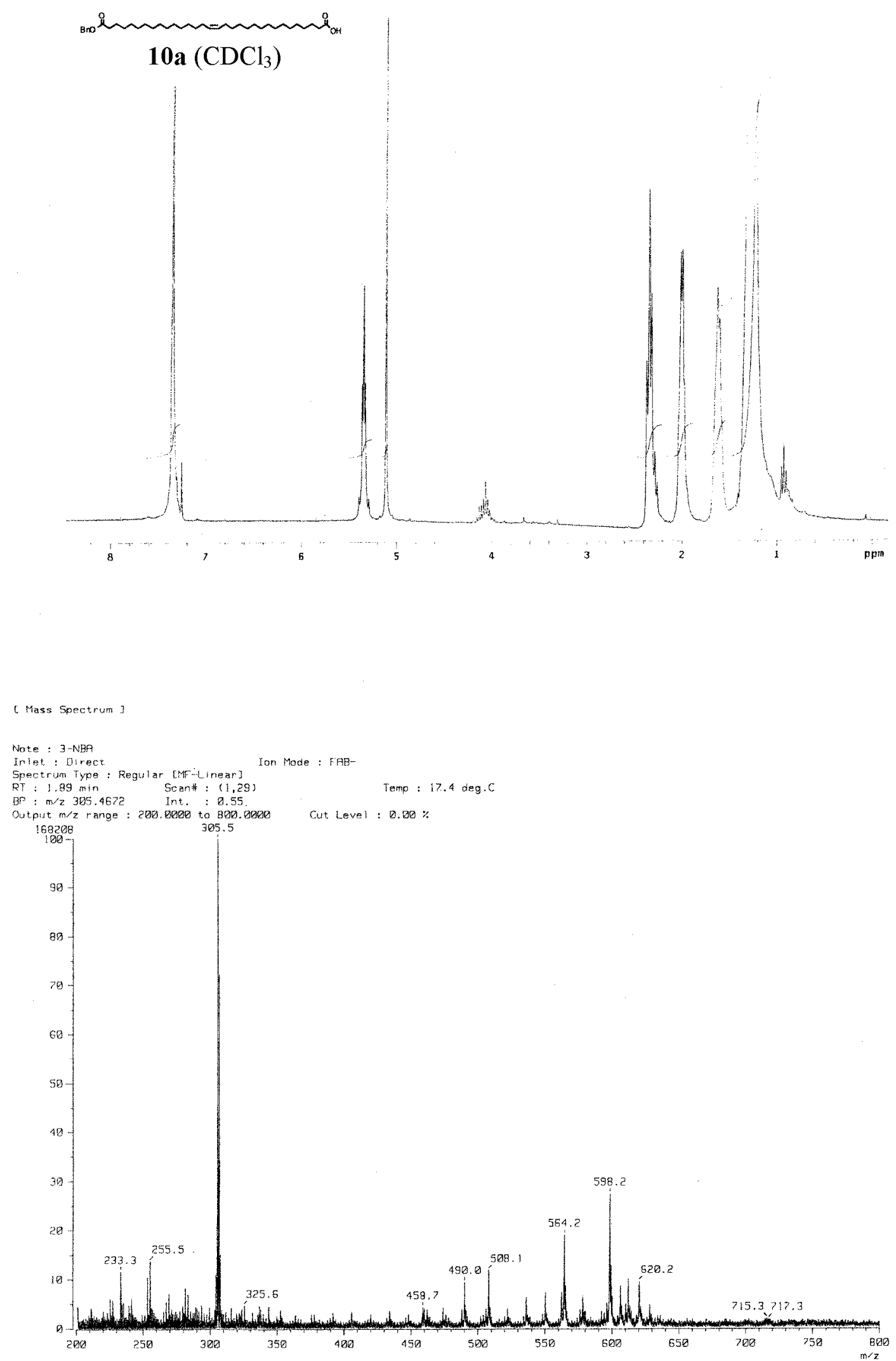


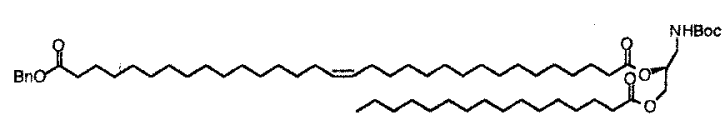

18a $\left(\mathrm{CDCl}_{3}\right)$
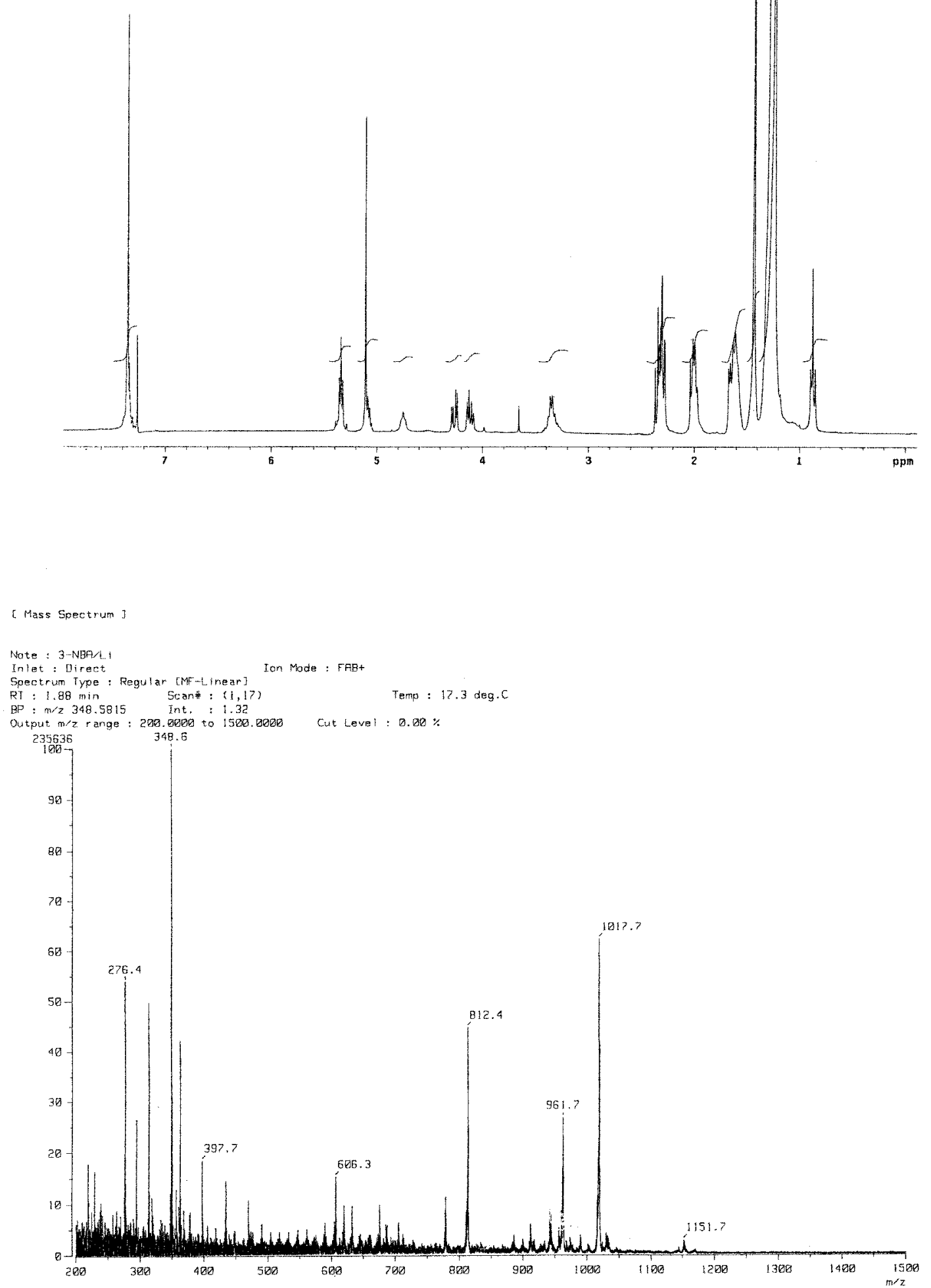


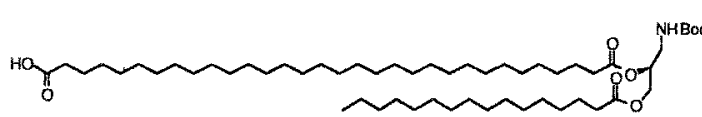

19a $\left(\mathrm{CDCl}_{3}\right)$
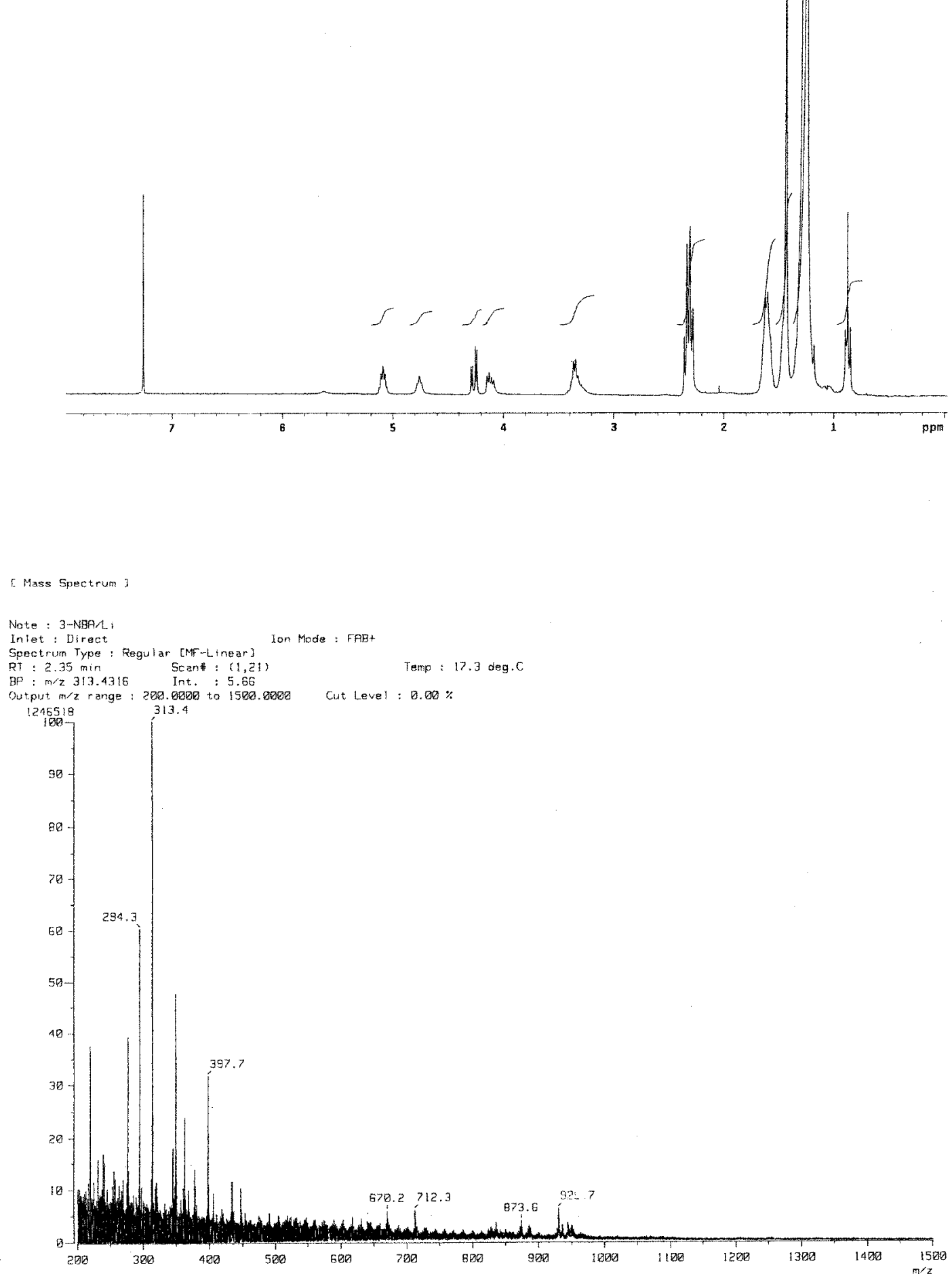

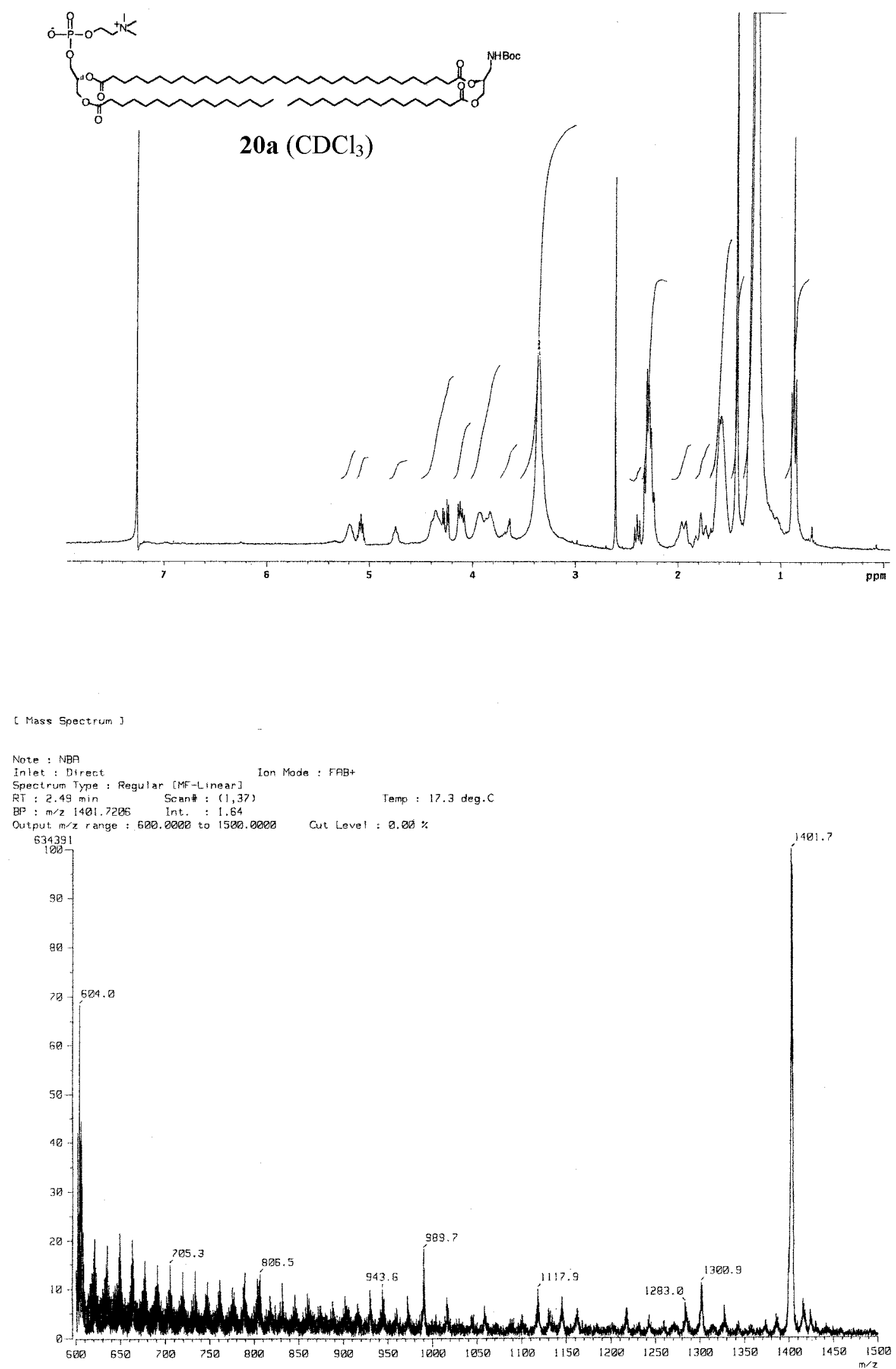

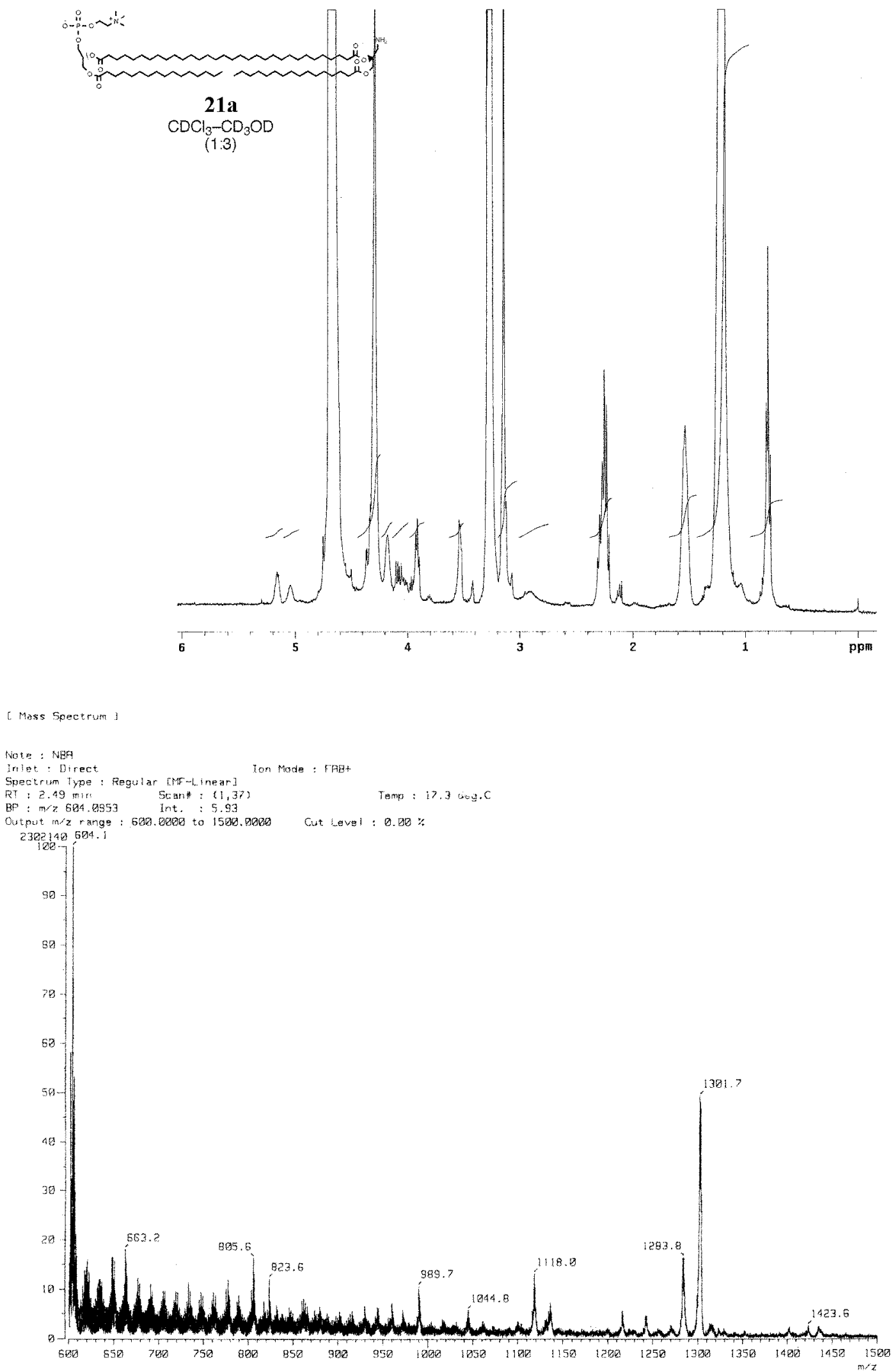